\title{
Contact Thermography as an Effective Tool for Detection of Breast Cancer in Women with Dense Breasts-A Case Report
}

\author{
Anna Ćwierz ${ }^{1}$, Agnieszka Byszek ${ }^{2,3}$, Marcin Trzyna ${ }^{2}$, Tadeusz J Popiela ${ }^{4}$ and Adrian Maciejewski ${ }^{5 *}$ \\ ${ }^{1}$ Department of Diagnostic Imaging, Ludwik Rydygier Memorial Specialized Hospital in Krakow, Poland \\ ${ }^{2}$ Braster SA, Poland \\ ${ }^{3}$ Centre of Oncology, Maria Skłodowska-Curie Memorial Institute, Poland \\ ${ }^{4}$ Department of Radiology, Jagiellonian University Collegium Medicum, Poland \\ ${ }^{5}$ Department of Rescue Medicine, Poznan University of Medical Sciences, Poland
}

*Corresponding author: Adrian Maciejewski, Department of Rescue Medicine, Poznan University of Medical Sciences, Poland, Tel: +48519 190 854; E-mail: maciejewski@ump.edu.pl

Received: 25 Aug, 2018 | Accepted: 26 Sep, 2018 | Published: 03 Oct, 2018

Citation: Ćwierz A, Byszek A, Trzyna M, Popiela TJ, Maciejewski A (2018) Contact Thermography as an Effective Tool for Detection of Breast Cancer in Women with Dense Breasts-A Case Report. J Breast Cancer Res Adv 1(2): dx.doi.org/10.16966/2638-3527.107

Copyright: (c) 2018 Ćwierz A, et al. This is an open-access article distributed under the terms of the Creative Commons Attribution License, which permits unrestricted use, distribution, and reproduction in any medium, provided the original author and source are credited.

\begin{abstract}
Breast cancer is the leading cause of death among women worldwide. Breast ultrasound and mammography examinations are routinely used to detect breast pathologies. Breasts have different breast densities (according to Wolfe's classification) and thus carry different risks of developing cancer. The existing routine screening methods have their limitation. Mammography has often been found to be insufficient for the examination of breasts with dense glandular tissue, as some cancerous changes may be undetected. Breast cancer, even at very early stages of development, has been found to have an increased rate of metabolism and therefore an increased temperature. These thermal changes, within the tumor core, can be detected using contact thermography. We present a case of an invasive ductal carcinoma in a patient with dense breast tissue, which was first detected via routine ultrasound examination and further confirmed through contact thermography. On mammography, the lesion was undetected. We discuss the potential for contact thermography to become a novel, non-invasive diagnostic tool which can be used as a complementary method to standard of care, especially for women with dense breast tissue, for whom mammography is not effective.
\end{abstract}

Keywords: Breast cancer; Contact thermography; Breast density

\section{Introduction}

Breast cancer is the most common malignant cancer and the leading cause of death in women worldwide [1]. It has become one of the most important health problems in recent decades. The detection rate of breast cancer has increased significantly due to increased awareness of the disease and increased availability of diagnostic tools, as well as implementation of national screening programs.

Due to the high risk of developing breast cancer in women with dense breast tissue, and the problems associated with selecting appropriate diagnostic examinations, breast cancer in these women is often detected at a more advanced stage [2]. There is an urgent need for improved diagnostic methods that can be used as complementary methods to standard of care. One such method is contact thermography, which utilizes a phenomenon of heat transmission to visualize changes in the breast glands. Through development of a pathological vessel system, cancer tissue has an increased metabolic activity compared to healthy tissue resulting in the presence of focal or linear hyperthermia's, which can be registered via contact thermography on liquid crystal matrices.

\section{Case}

A 39-year old woman came in to the clinic for a routine ultrasound breast examination. The physical examination was unremarkable. A breast ultrasound was performed, which revealed a $17 \times 24 \mathrm{~mm}$, irregular, hypoechoic change, partially obscured, located in the left breast at the 5 oclock axis (Figure 1). The change was classified as BIRADS $4 \mathrm{C}$ and the patient was referred for mammography and coreneedle biopsy.

A mammography was performed prior to the planned biopsy. The mammogram revealed dense, glandular breasts, without visible micro-calcifications. In the upper outer quadrant of the left breast, an asymmetric density (Figure 2-circled structure) was visualized, which qualified the patient for a secondary ultrasound evaluation. Based on the type of breast tissue (dense glandular tissue according to Wolfe's classification), mammographic examination has reduced sensitivity [3]. The change was classified as BI-RADS 0.

Both breasts have dense, glandular tissue, BI-RADS 0. An asymmetric density in the upper outer quadrant of the left breast is circled, which qualified for an additional ultrasound evaluation. 


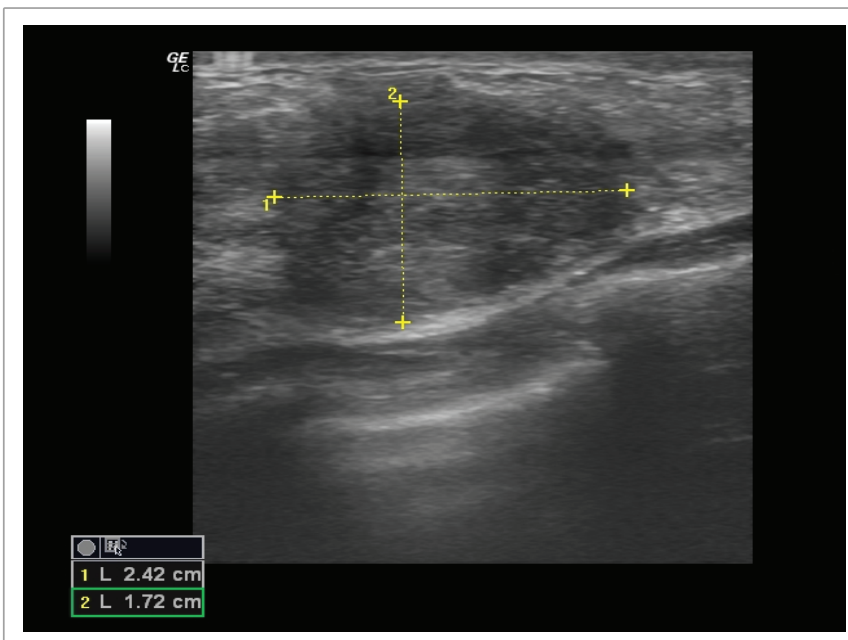

Figure 1: Ultrasound examination of the left breast revealed a 17 $\times 24 \mathrm{~mm}$ solid change in the lower outer quadrant, Classified as BI-RADS 4c.

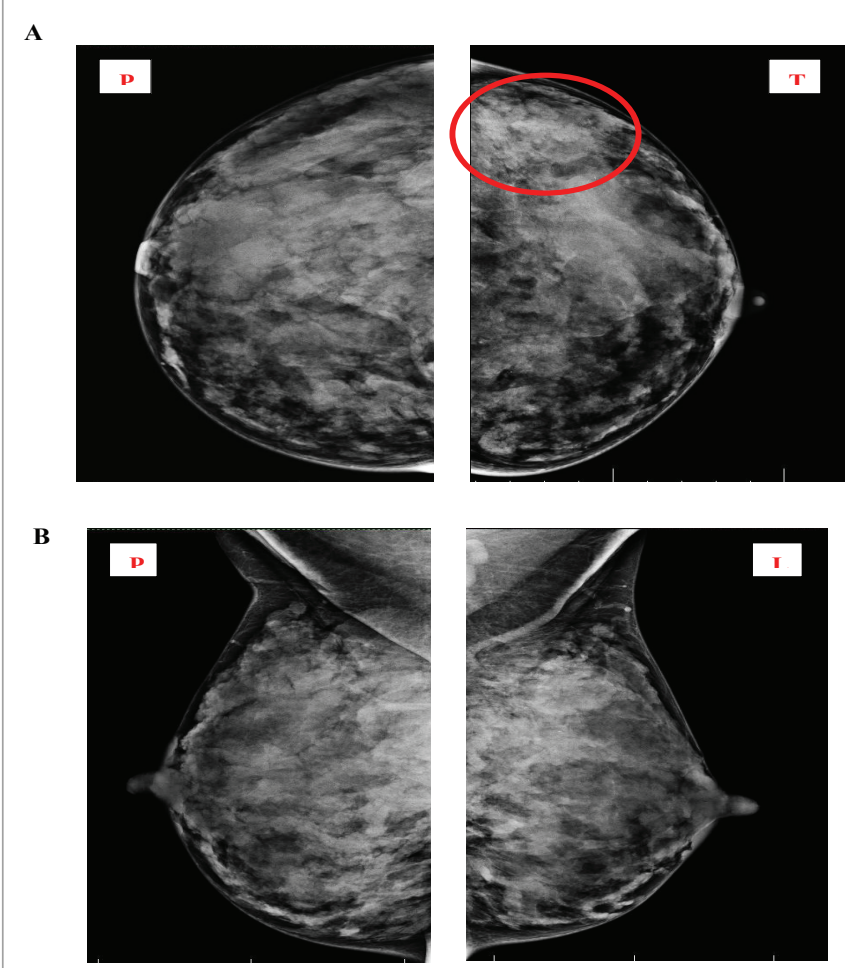

Figure 2: Mammogram of both breasts in CC (cranio-caudal) and MLO (mediolateral oblique) view.

The patient was referred to a diagnostic center, in which a secondary ultrasound examination was performed. No changes were detected in the area described in the mammogram, but a solid change in the lower outer quadrant of the left breast at the 5 o'clock axis was confirmed. Next a thermographic examination was performed of both breasts (Figure 3). A focal hyperthermic structure was observed in the lower outer quadrant of the left breast, in the location previously visualized on the ultrasound examination. No significant thermal changes were detected in the right breast.
Due to the appearance of a suspicious change in the left breast, a core-needle biopsy was performed, which confirmed a grade 2 invasive ductal carcinoma, type NOS (Not Otherwise Specified).

\section{Discussion}

\section{Thermography-principles in breast diagnostics}

The underlying physiological principle of contact thermography in medical imaging diagnostics is the so-called dermo-themal effect, in which cancer cells have a higher rate of metabolism [4]. Furthermore, a process of neo-angiogenesis induces strong hypervascularization around the tumor core, which can occur even at very early stages of cancer development [5]. It has been shown that even within a microenvironment of a $1 \mathrm{~mm}$ diameter tumor, there are enough pro-angiogenic factors to generate completely new vasculature [6,7]. This phenomenon leads to permanent, localized, intra-glandular temperature anomalies, which can be observed on the surface of the examined organ [8].

Instruments based on contact thermography, through the application of a liquid crystal foil, can induce a so-called selective light diffraction effect. This effect allows us to obtain a color image on the surface of the liquid crystal foil. By pressing the foil against the surface of the breast, a color thermogram is obtained, the analysis of which enables us to detect hyper-vascular changes in the breast.

A retrospective observational population study performed by Bothmann, et al. [9] on 19,461 females showed that abnormal thermography results were obtained in $86 \%$ of women with confirmed malignant lesions. Sensitivity and specificity of contact thermography for all invasive neoplastic lesions was $73 \%$ and $71 \%$, respectively, with a false positive rate of $16.6 \%$ and false negative of $8.6 \%$.

\section{Breasts with dense tissue-characteristics and methods of evaluation}

Numerous classification approaches for the characterization of breast density have been proposed, most commonly used is Wolfe's classification, which relies on mammographic examination of the fibro-glandular densities in relation to fat tissue (Figure 4). Wolfe first proposed this classification system in 1976, following his retrospective study of 7,214 women [10]. Based on roentgen images and several years of observation, Wolfe selected and named specific categories of breast parenchymal patterns [11]. Wolfe then classified women into four groups (N1,P1,P2, and DY), each group with a different risk of developing breast cancer.

Due to the differences in breast densities and the resulting consequences, there is an increased need to evaluate breast density during routine screening examinations. According to a new legislation passed in February 2014 in the US [12], women undergoing mammography screening must be directly informed if they have dense breast tissue. This is because there is lack of female awareness of different breast densities and the associated risks of developing cancer, as well as lack of knowledge among doctors about potential false negative mammograms where a dense breast tissue can mask the tumor [11]. With increasing number of research reports and publications $[13,14]$ relating to the increased risk of breast cancer in women with dense breast tissue, numerous educational organizations have been founded worldwide, which promote routine screening and provide help and support to women. 

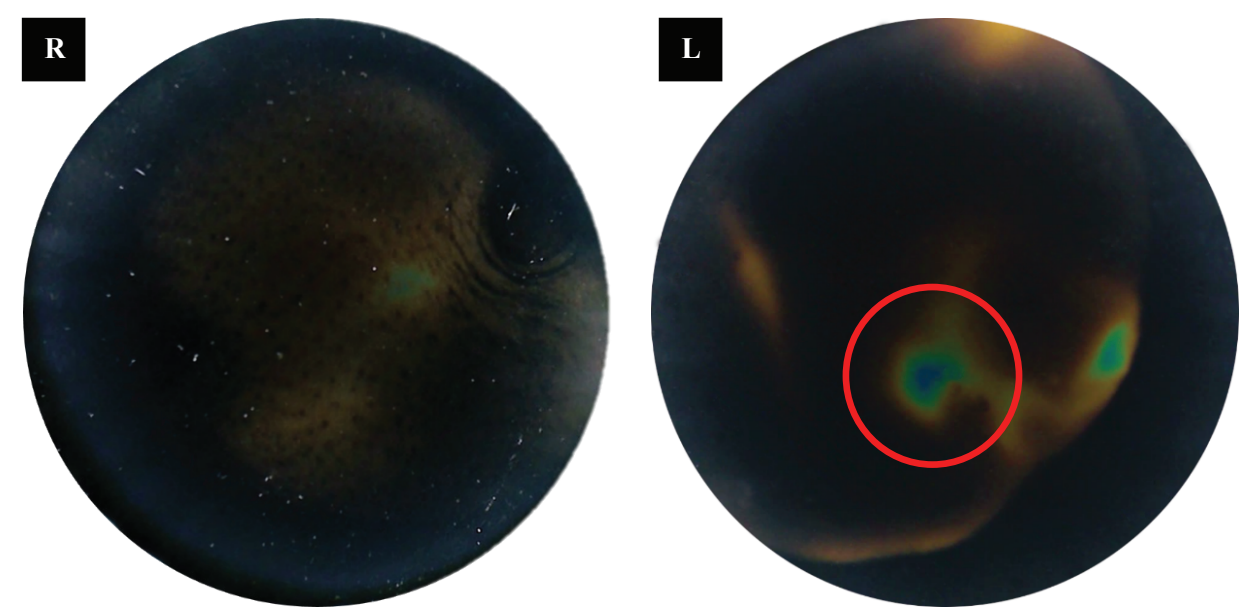

Figure 3: Contact thermography of the lower outer quadrants of both breasts reveals focal hyperthermia in the left breast (circled).
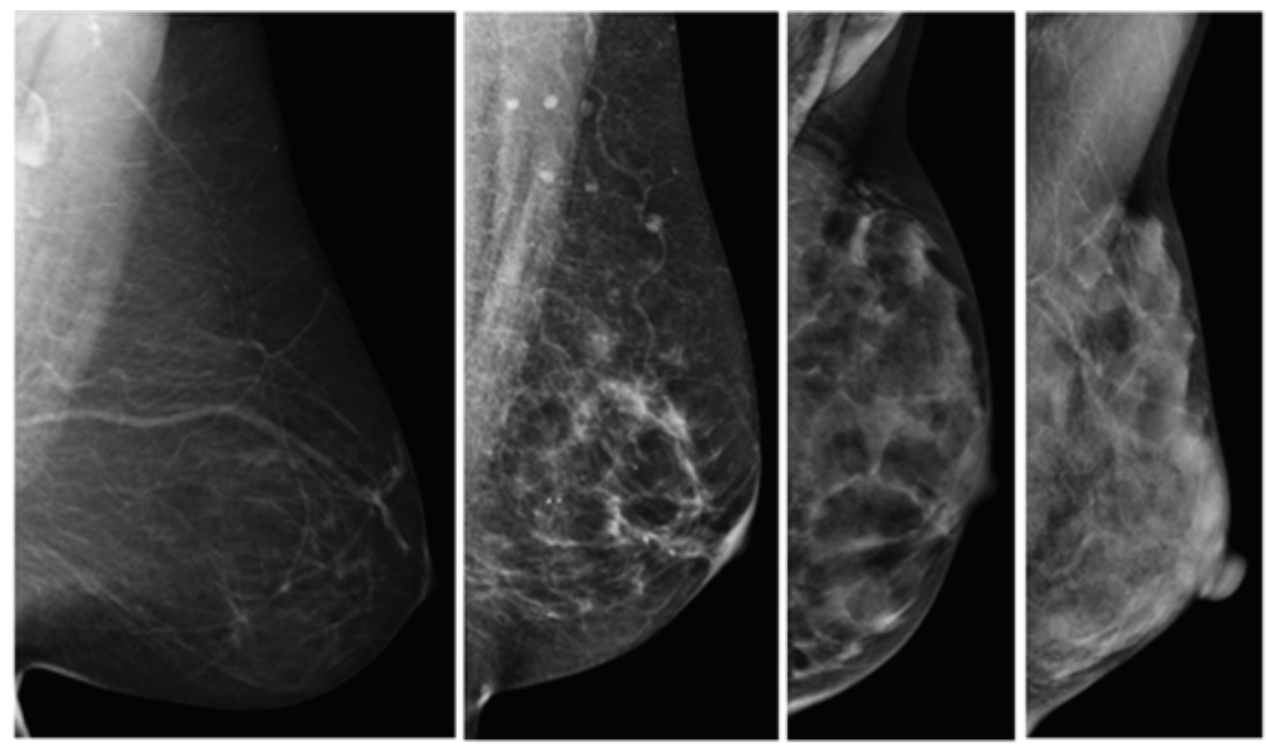

Figure 4: Mammogram classification of breast tissue based on Wolfe's classification (left to right: N1,P1,P2,DY).

Diagnosing breast cancer in women with dense breasts-a methods approach

To date, there are various imaging techniques to visualize breast cancer at various stages, including: mammography, ultrasound, MRI, and most recently, thermography [15-17]. In women with dense breasts, the sensitivity of mammography can be as low as 30-45\% [18]. Dense breast tissue decreases the sensitivity as well as specificity with which screening mammography is able to diagnose the cancer. Over 50 percent of females participating in breast cancer screening programs have intermediary dense breasts or extremely dense breasts [19]. Henceforth, an increased amount of dense breasts are observed, with the limited sensitivity of screening mammography. Complementary nonmammographic imaging tools have been proposed, including breast MR and ultrasound. Breast MR has a high specificity (97.1\%) and positive predictive value (35\%), however with increased cost, requirement of intravenous contrast and low sensitivity, breast MR has not become part of routine screening [20]. Complementary breast ultrasound on the other hand has been shown to have a high sensitivity
(91.1\%), however a lower specificity (87.7\%), and low positive predictive value, which may translate to higher costs downstream and increased morbidity [21].

Regulations set forth by the US Food and Drug Administration have cleared thermography as an adjunctive tool to mammography, which is similar to the aforementioned methods [22]. By no means should thermography be used as a standalone method for breast cancer screening or diagnosing early stage breast cancer. Thermography, as an alternative option in the diagnostic pathway, may be used to complement current standards as it is inexpensive, non-invasive, and far more portable than the aforementioned modalities. Further studies are required to see the impact on healthcare costs and its role in breast cancer screening.

\section{Conclusion}

In the presented case, analysis of the performed examinations demonstrated the limitations of mammography; while, providing a glimpse for the potential of contact thermography as an appropriate 
technique for evaluating metabolic changes first detected on breast ultrasound.

Contact thermography is a non-invasive method that does not use radiation and can play a significant adjunctive role in the early detection of breast cancer. Contact thermography is particularly useful in women with dense breast tissue, who have an increased risk of developing breast cancer but for whom mammography is not an effective diagnostic method.

\section{Conflicts of Interest}

$\mathrm{AN}, \mathrm{AB}, \mathrm{MT}$ and $\mathrm{TP}$ have received compensation from Braster SA for consultancy and services provided with relation to this study.

\section{References}

1. International Agency for research on Cancer (2012) GLOBOCAN 2012: Cancer Fact sheet.

2. Van der Waal D, Ripping TM, Verbeek AL, Broeders MJ (2017) Breast cancer screening effect across breast density strata: a case-control study. Int J Cancer 140: 41-49.

3. Checka CM, Chun JE, Schnabel FR, Lee J, Toth H (2012) The relationship of mammographic density and age: implications for breast cancer screening. AJR Am J Roentgenol 198: W292-W295.

4. Gautherie M (1983) Thermobiological assessment of benign and malignant breast diseases. Am J Obstet Gynecol 147: 861-869.

5. Folkman J (1971) Tumor angiogenesis: Therapeutic implications. N Engl J Med 285: 1182-1186.

6. Liotta LA, Kohn EC (2001) The microenvironments of the tumor host interface. Nature 411: 375-379.

7. Senger DR, Galli SJ, Dvorak AM, Perruzzi CA, Harvey VS, et al. (1983) Tumor cells secrete a vascular permeability factor that promotes accumulation of ascites fluid. Science 219: 983-985.

8. Popiela TJ, Ćwierz A, Pypkowska A, Trzyna M (2016) Thermographic Atlas: Breast Cancer. $1^{\text {st }}$ Edition. Warsaw: Wydawnictwo Lekarskie PZWL.

9. Bothmann G, Bussche U, Kubli F, Seybold G (1974) Plate thermography-a new method in the diagnosis of breast cancer. Dtsch med Wochenschr 99: 730-734.

10. Wolfe JN (1976) Breast patterns as an index of risk for developing breast cancer. AJR Am J Roentgenol 126: 1130-1137.
11. Wolfe JN (1976) Risk for breast cancer development determined by mammographic parenchymal pattern. Cancer 37: 2486-2492.

12. Freer PE, Slanetz PJ, Haas JS, Tung NM, Hughes KS, et al. (2015) Breast Cancer screening in the era of density notification legislation: summary of 2014 Massachusetts experience and suggestion of an evidence-based management algorithm by multi-disciplinary expert panel. Breast Cancer Res Treat 153: 455-464.

13. Bae JM, Kim EH (2016) Breast Density and Risk of Breast Cancer in Asian Women: A Meta-analysis of Observational Studies. J Prev Med Public Health 49: 367-375.

14. Moothathu NS, Philpotts LE, Busch SH, Gross CP, Staib LH, et al. (2017) Knowledge of Density and Screening Ultrasound. Breast J 23: 323-332.

15. EYK Ng (2009) A review of thermography as promising non-invasive detection modality for breast tumor. Int J Therm Sci 48: 849-859.

16. Bonnema J, van Geel AN, van Ooijen B, Mali SP, Tjiam SL, et al. (1997) Ultrasound-guided aspiration biopsy for detection of nonpalpable axillary node metastases in breast cancer patients: new diagnostic method. World J Surg 21: 270-274.

17. Schnall MD, Blume J, Bluemke DA, Deangelis GA, Debruhl N, et al. (2005) MRI detection of distinct incidental cancer in women with primary breast cancer studied in IBMC 6883. J Surg Oncol 92: 320338.

18. Leibman AJ, Kruse B (1990) Breast cancer: mammographic and sonographic findings after augmentation mammoplasty. Radiology 174: 195-198.

19. Kerlikowske K, Zhu W, Hubbard RA, Geller B, Dittus K, et al. (2013) Outcomes of screening mammography by frequency, breast density, and postmenopausal hormone therapy. JAMA Intern Med 173: 807816.

20. Kuhl CK, Strobel K, Bieling H, Leutner C, Schild HH, et al. (2017) Supplemental Breast MR Imaging Screening of Women with Average Risk of Breast Cancer. Radiology 283: 361-370.

21. Ohuchi N, Suzuki A, Sobue T, Kawai M, Yamamoto S, et al. (2016) Sensitivity and specificity of mammography and adjunctive ultrasonography to screen for breast cancer in the Japan Strategic Anti-cancer Randomized Trial (J-START): a randomised controlled trial. Lancet 387: 341-348.

22. US Food and Drug Administration (USFDA) (2017) Breast Cancer Screening: Thermogram No Substitute for Mammogram. USFDA. 